\title{
Transport Properties, Mechanical Behavior, Thermal and Chemical Resistance of Asymmetric Flat Sheet Membrane Prepared from PSf/PVDF Blended Membrane on Gauze Supporting Layer
}

\author{
Nita Kusumawati ${ }^{1 *}$, Pirim Setiarso ${ }^{1}$, Maria Monica Sianita ${ }^{1}$, and Supari Muslim² \\ ${ }^{1}$ Department of Chemistry, Faculty of Mathematics and Science, Universitas Negeri Surabaya, \\ Jl. Ketintang, Surabaya 60231, Indonesia \\ ${ }^{2}$ Department of Electrical Engineering, Faculty of Engineering, Universitas Negeri Surabaya, \\ Jl. Ketintang, Surabaya 60231, Indonesia
}

Received August 4, 2017; Accepted January 3, 2018

\begin{abstract}
Asymmetric polysulfone (PSf) membrane is prepared using phase inversion method and blending with polyvinylidene fluoride (PVDF) on the gauze solid support. Casting solution composition optimization has been done to get PSf/PVDF membrane with best characteristics and permeability. The result shows that blending on PSf with PVDF polymer using phase inversion method has been very helpful in creating an asymmetric porous membrane. Increased level of PVDF in casting solution has increased the formation of asymmetry structure and corresponding flux membrane. The result from a thermal test using Differential Scanning Calorimetry (DSC)-Thermal Gravimetric Analysis (TGA) shows the resistance of the membrane to temperature $460{ }^{\circ} \mathrm{C}$. Membrane resistance against acid looks from undetectable changes in infrared spectra after immersion process in $\mathrm{H}_{2} \mathrm{SO}_{4} 6-98 \mathrm{~V} / \mathrm{v} \%$. While membrane color changes from white to brownish and black is detected after the immersion process in sodium hydroxide (NaOH) $0.15-80 w / v \%$.
\end{abstract}

Keywords: membranes; polysulfone; polyvinylidene fluoride; blending; synthesis processing

\section{ABSTRAK}

Membran asimetri polysulfone dipreparasi dengan metode inversi fasa dan blending menggunakan poliviniliden florida pada padatan pendukung kasa. Optimasi komposisi larutan cetak telah dilakukan untuk mendapatkan membran PSf/PVDF dengan karakteristik dan permeabilitas terbaik. Hasil menunjukkan bahwa blending PSf dengan polimer PVDF menggunakan metode inversi fasa telah sangat membantu menciptakan pori asimetri pada membran. Peningkatan kadar PVDF dalam larutan cetak telah meningkatkan formasi struktur asimetri dan fluks membran yang bersangkutan. Hasil uji termal menggunakan analisis Differential Scanning Calorimetry (DSC)-Thermal Gravimetric (TGA) menunjukkan ketahanan membran hingga temperatur $460^{\circ} \mathrm{C}$. Ketahanan membran terhadap asam tampak dari tidak terdeteksinya perubahan pada spektra infra merah setelah proses perendaman dalam $\mathrm{H}_{2} \mathrm{SO}_{4} 6-98 \% \mathrm{~V} / \mathrm{V}$. Sementara itu, perubahan warna membran dari putih menjadi coklat dan hitam terdeteksi setelah proses perendaman dalam $\mathrm{NaOH} 0,15-80 \% \mathrm{w} / \mathrm{v}$.

Kata Kunci: membrane; polysulfone; poliviniliden florida; blending, and proses sintesis

\section{INTRODUCTION}

Membrane technology has many advantages including low energy consumption and high separation efficiency [1]. However, the fouling membrane has been shortening membrane lifetime and causing increased costs, therefore it has been blocking its application on a large scale industry [2]. Research and development of new membrane materials is an effective way to suppress the fouling membrane. Membrane materials should be commercially available, have a thermal stability and good chemical resistance against acids and bases as

${ }^{*}$ Corresponding author.

Email address : nkusumawati82@yahoo.com well as good mechanical strength and characteristics [3-6].

Microporous polymer membrane has been used extensively in many separation processes. For such purposes, pore structure is an important factor considered in membrane manufacturing process [7]. The good porous membrane should have a high permeability and chemical resistance to the flow of feed solution. Asymmetric membrane is one of the ideal selection parameters to get high permeability [8].

Phase inversion process induced by immersion precipitation is used to manufacture asymmetric membranes [9-10]. When a thin layer of casting

Nita Kusumawati et al. 
solution immersed in coagulation medium, the solvent in the casting solution was replaced by the nonsolvent. This process has resulted in asymmetry membrane with dense top layer and porous sublayer which is composed of macrovoids, pore, and micropore [11]. Pore size and porosity of the membrane is influenced by the relative diffusion rate of solvent and nonsolvent. The formation of sublayer controlled by changing on casting solution and nonsolvent compositions as well as operational conditions such as stirring time and casting thickness [12].

In membrane manufacture, PSf is known for its characteristics include a good solubility in a number of aprotic polar solvent (dimethylformamide (DMF), dimethylacetamide (DMAc), dimethyl sulfoxide (DMSO), halogen derivatives, nitrobenzene, high thermal resistance $\left(150-170{ }^{\circ} \mathrm{C}\right)$, high chemical resistance almost on the entire range of $\mathrm{pH}$ and oxidative medium (hypochloride $5-7 \%$, hydrogen peroxide $3-5 \%$ ) as good as mechanical strength [13]. However, the use of PSf is limited because of the symmetry structure as well as a limited range of pore size and porosity. The symmetry membrane has higher mass transfer resistance than the asymmetry membrane. These conditions magnify fouling potential on the membrane surface and internal pore. The membrane lifetimes decrease will go hand in line with the increasing of fouling membrane. Some of the methods that can be done to eliminate the weakness of PSf is blending PSf polymer with another polymer material that capable of forming a dense membrane with asymmetry structure, such as PVDF [14].

Compared with many other organic polymer materials, PVDF is a material that is widely used in the manufacturing process of the microfiltration (MF), ultrafiltration (UF), and pervaporation (PV) membrane because of its excellent thermal stability and chemical resistance against acids, bases, and organic solvents [15]. In addition, PVDF membrane obtained from phase inversion process has a good mechanical strength and asymmetry structure that required for separation. Therefore, PSf membrane preparation with blending method using PVDF material will generate membrane which not only has a good thermal and chemical resistance, mechanical strength but also has higher fouling resistance.

\section{EXPERIMENTAL SECTION}

\section{Materials}

Polysulfone (PSf; $d=1.24 \mathrm{~g} \mathrm{~L}^{-1}$ at $25{ }^{\circ} \mathrm{C} ; \mathrm{Mw}$ 35,000; Sigma Aldrich) and polyvinylidene fluoride (PVDF; Mw 354,000; Aldrich) used as membrane material. 1-methyl-2-pyrrolidone (NMP; biotech grade; $\geq 99.7 \%$; Sigma Aldrich) used as polymer solvent.
Ammonium chloride $\left(\mathrm{NH}_{4} \mathrm{Cl} ; \geq 99.5 \%\right.$; Riedel de Haen) used as membrane pore-forming additive, while gauze fabric (Kasa Husada Indonesia, 254 mesh) used as membrane supporting layer. Distilled water is used as a nonsolvent for the polymer precipitation. Meanwhile, sulfuric acid $\left(\mathrm{H}_{2} \mathrm{SO}_{4}\right.$; > 98\%; Ajax Finichem Pty Ltd.) and sodium hydroxide ( $\mathrm{NaOH}$; pellet; $\geq 98 \%$; Sigma Aldrich) are used in order to test the membrane chemical resistance.

\section{Instrumentation}

Surface and cross-section morphology of the PSf/PVDF membranes were observed using ZEISS EVO MA 10 Scanning Electron Microscope (SEM). The mechanical strength of the membrane was analyzed using RCT-10KN-AF Toyo Seiki Strograph. The permeation performance of the PSf/PVDF membrane was carried out by dead-end membrane reactor (selfmade) with distillate water as feed solution. The thermal decomposition of the membrane was analyzed by Perkin Elmer STA-6000 Differential Scanning Calorimetry (DSC)-Thermal Gravimetric Analysis (TGA). Thermogravimetric analysis under an $\mathrm{N}_{2}$ atmosphere from 0 to $890{ }^{\circ} \mathrm{C}$ with a heating rate of $10{ }^{\circ} \mathrm{C} \mathrm{min}^{-1}$. The chemical decomposition of the membrane before and after chemical resistance test was analyzed by Nicolet IS10 Thermo Scientific Fourier Transform Infra-Red (FTIR).

\section{Procedure}

\section{Casting solution preparation}

For the preparation of the membrane, as much as $2 \mathrm{~g}$ of PSf and $2 \mathrm{~g}$ of $\mathrm{NH}_{4} \mathrm{Cl}$ are dissolved in $84 \mathrm{~g}$ solvent NMP. Furthermore, to ensure the formation of homogeneous casting solution done stirring using NESCO LAB MS-H280-Pro magnetic stirrer for $105 \mathrm{~min}$ at a temperature of $60{ }^{\circ} \mathrm{C}$. After that, while continuing to stir using stirrer, into membrane casting solution added $12 \mathrm{~g}$ of PVDF. The stirring process of casting solution continued for $30 \mathrm{~min}$. To get optimum casting solution composition the preparation of casting solution done by following casting solution composition that looks at Table 1.

Table 1. Composition of PSf/PVDF solutions

\begin{tabular}{|c|c|c|c|c|}
\hline Membrane & PSf & PVDF & NMP & $\mathrm{NH}_{4} \mathrm{Cl}$ \\
\hline M1 & 14 wt\% & 0 wt $\%$ & 84 wt\% & $2 \mathrm{wt} \%$ \\
\hline M2 & $0 \mathrm{wt} \%$ & 14 wt\% & 84 wt\% & $2 \mathrm{wt} \%$ \\
\hline M3 & $8 w t \%$ & $6 \mathrm{wt} \%$ & 84 wt\% & $2 \mathrm{wt} \%$ \\
\hline M4 & $7 \mathrm{wt} \%$ & $7 \mathrm{wt} \%$ & 84 wt\% & $2 w t \%$ \\
\hline M5 & $6 w t \%$ & $8 w t \%$ & 84 wt\% & $2 w t \%$ \\
\hline M6 & $3 w t \%$ & 11 wt\% & $84 w t \%$ & $2 w t \%$ \\
\hline
\end{tabular}




\section{Membrane preparation}

The PSf/PVDF membrane which is prepared using phase inversion method are generally used for the preparation of various types of asymmetry membrane. The solution is cast on a glass sheet which coated with gauze fabric supporting layer using casting knife method at temperature $80{ }^{\circ} \mathrm{C}$ and thickness $800 \mu \mathrm{m}$. Subsequently, membrane transferred in the coagulation medium for immersion precipitation process on temperature $60{ }^{\circ} \mathrm{C}$. The nonsolvent used is distilled water. Throughout the rest of the solvent and pore forming agent is removed by immersing in distilled water for $24 \mathrm{~h}$. After casting, the membrane is removed from the glass sheet.

\section{Membrane characterization}

The membrane cross section prepared by breaking at the temperature of liquid nitrogen. The entire membrane is coated with a thin layer of gold before it is tested using Zeiss EVO MA10 Scanning electron microscope (SEM). The result from SEM shows surface, cross section, and pore sizes of PSf/PVDF membrane.

In order to know the permeation performance of PSf/PVDF membrane, the permeability is tested using dead-end filtration system with pure water as feed solution. The PSf/PVDF membrane permeability is calculated using Eq. 1:

$\mathrm{J}=\frac{\mathrm{V}}{\mathrm{AT}}$

where $\mathrm{V}$ is the volume of permeate in a liter, $\mathrm{A}$ is the membrane surface area $\left(\mathrm{m}^{2}\right)$, and $\mathrm{T}$ is the permeation time (h). Minimum three membrane samples were tested and the permeability tabulation result showed the average value.

Meanwhile, the PSf/PVDF membrane mechanical characterization is conducted by measuring the mechanical strength of membrane using RCT-10KN-AF Toyo Seiki Strograph. The mechanical strength of PSf/PVDF membrane evaluated using Young's modulus that is calculated based on the ratio between load and stroke as seems on Eq. 2:

$E=\frac{\text { stress }}{\text { strain }}$

where stress is the magnitude of forces that acting in the unit area of the material in $\left(\mathrm{Nm}^{-2}\right)$, and strain is the ratio of value added material to the initial length. Minimum three membrane samples were tested and the mechanical strength tabulation result showed the average value.

\section{Membrane chemical resistance test}

The chemical resistance test of the PSf/PVDF membrane is carried out by immersing the membrane cutting in sulfuric acid $\left(\mathrm{H}_{2} \mathrm{SO}_{4}\right)$ solution $98 \%(\mathrm{v} / \mathrm{v})$ and sodium hydroxide $(\mathrm{NaOH})$ 80\% (w/v) for $24 \mathrm{~h}$. Further, to know the changes that occur after immersing treatment of membrane in acid and base solution has been carried out an analysis of the PSf/PVDF membrane functional groups using Nicolet IS10 Thermo Scientific Fourier Transform Infra-Red (FTIR).
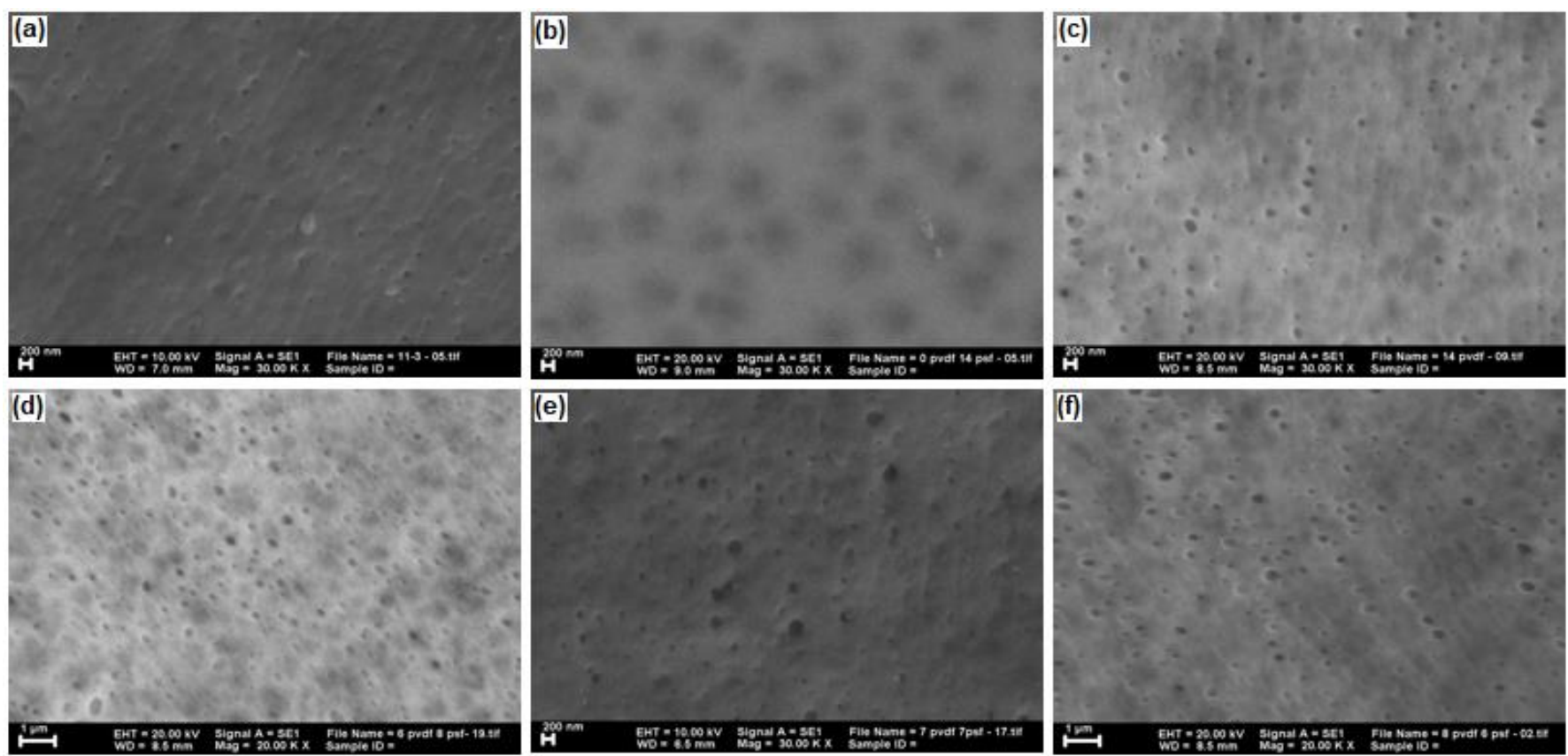

Fig 1. SEM images of PSf/PVDF membranes surface with four casting solution compositions. (a) M3; (b) M4; (c) M5; (d) M6; (e) M1; and (f) M2 

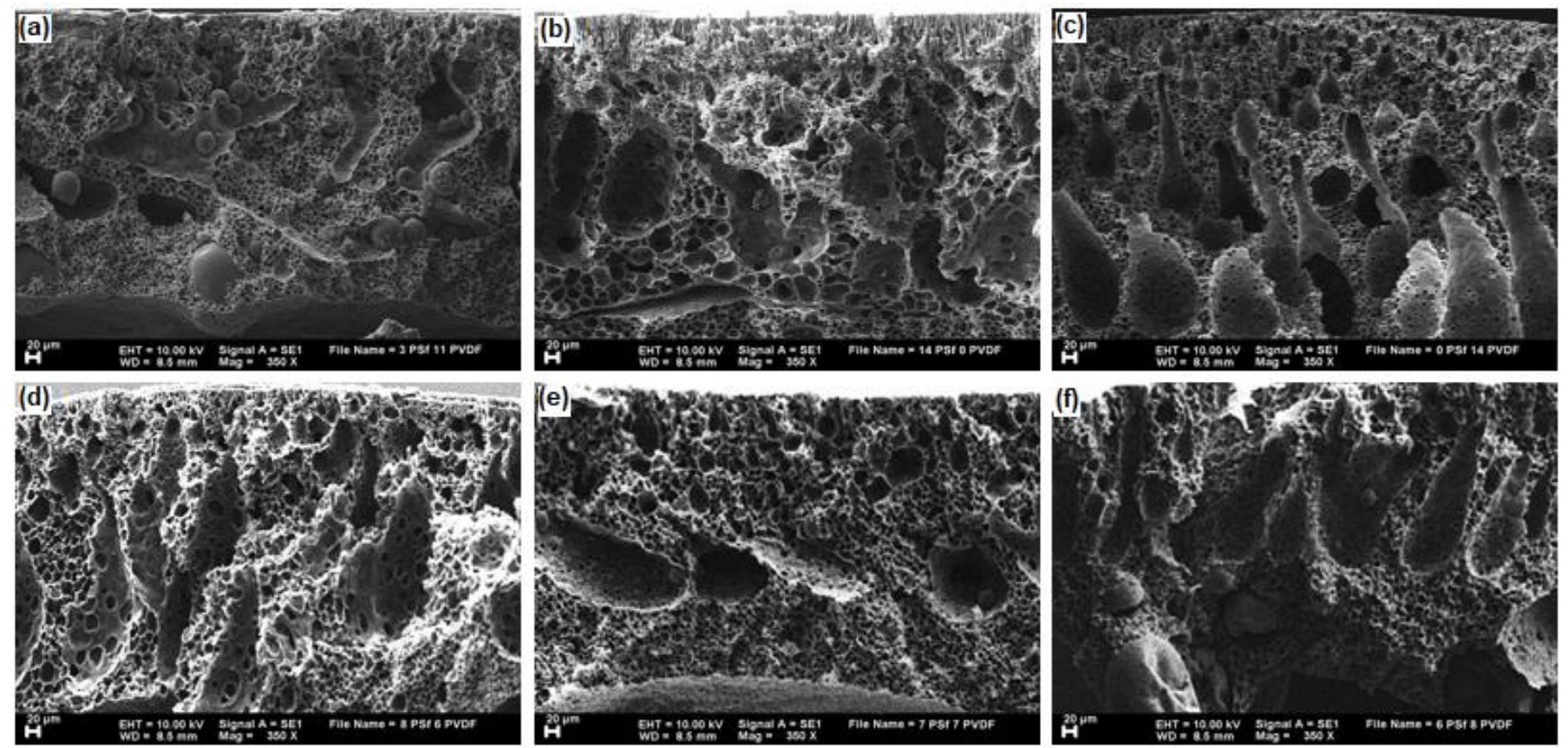

Fig 2. SEM images of PSf/PVDF membranes cross section with four casting solution compositions. (a) M3; (b) M4; (c) M5; (d) M6; (e) M1; and (f) M2

\section{Membrane thermal stability test}

The thermal stability test of the PSf/PVDF membrane is carried out through evaluation of mass changes using Perkin Elmer STA-6000 Differential Scanning Calorimetry (DSC)-Thermal Gravimetric Analysis (TGA).

\section{RESULT AND DISCUSSION}

\section{Membrane Characterization}

\section{Membrane cross-section analysis}

The result of PSf/PVDF membrane surface and cross-section morphology analysis with various casting solution compositions seems at Fig. 1-2. Fig. 1 shows SEM micrographs of PSf/PVDF, PSf, and PVDF membrane surface morphology and Fig. 2 shows SEM micrographs of PSf/PVDF, PSf, and PVDF membrane cross-section morphology. From Fig. 2 seems obvious asymmetry structure in membrane M3, M4, M5, and M6. The cross-section morphology data in Fig. 2 shows that compared with membrane M4, M5, and M6, membrane M3 has highest porous layer thickness with biggest pore size. This shows that the addition of an increased level of PVDF on PSf polymer solution has led to decrease the thickness and the pore size of the porous layer on the membrane. This is because the PVDF polymer tends to fill the membrane framework which is dominated by the PSf.
Fig. 2 shows that the PSf/PVDF membrane is manufactured from phase inversion process forming the characteristic structure of macrovoid. The solventnon solvent system produced by a combination of NMP-water has a high mutual affinity which means that fast liquid-liquid demixing process will occur during the phase transition. According to SEM image of PSf and PVDF membranes in Fig. $2 e$ and $2 f$, it is obviously seems that the addition of PVDF polymer in PSf polymer solution has formed membrane with lower thickness and pore size of porous layer, and instead, the addition of PSf polymer in PVDF polymer solution has led to increasing the thickness and pore size of porous layer on PSf/PVDF membrane.

The molecular structure of the more long chain on PSf compared with PVDF has caused the forming of more porous surface and internal pore sizes with a higher thickness of the porous layer on PSf membrane. In line with this, the much higher molecular weight of PVDF used has created smaller pore sizes with a lower thickness of the porous layer on PSf/PVDF membrane with higher PVDF content.

\section{Membrane mechanical strength analysis}

The lower thickness of a porous layer on crosssection structure of PSf/PVDF membrane produced from casting solution with higher PVDF content has impacted on the lower mechanical strength of the concerned membrane. In Table 2 looks mechanical 
Table 2. Mechanical strength of PSt/PVDF membrane

\begin{tabular}{|c|c|c|c|c|c|}
\hline Membrane & PSf & PVDF & NMP & $\mathrm{NH}_{4} \mathrm{Cl}$ & Young's Modulus $\left(\mathrm{Nm}^{-2}\right)$ \\
\hline M1 & 14 wt $\%$ & $0 w t \%$ & $84 \mathrm{wt} \%$ & $2 w t \%$ & 1523.8 \\
\hline M2 & $0 \mathrm{wt} \%$ & $14 w t \%$ & 84 wt\% & $2 w t \%$ & 647.2 \\
\hline M3 & $8 w t \%$ & 6 wt $\%$ & 84 wt\% & 2 wt\% & 991.4 \\
\hline M4 & $7 \mathrm{wt} \%$ & $7 w t \%$ & 84 wt\% & 2 wt\% & 962.1 \\
\hline M5 & $6 \mathrm{wt} \%$ & $8 w t \%$ & 84 wt\% & 2 wt\% & 938.3 \\
\hline M6 & $3 \mathrm{wt} \%$ & 11 wt $\%$ & 84 wt $\%$ & $2 w t \%$ & 662.3 \\
\hline
\end{tabular}

strength data of PSf/PVDF, PSf, and also PVDF membrane used as a control. The lower thickness of porous layer in PSf/PVDF membrane as a result of higher PVDF polymer addition has decreased the ability of membrane to maintain its pore sizes when applied high operating pressure (for example, from $991.4 \mathrm{Nm}^{-2}$ for membrane $\mathrm{M} 3$ to $962.1 \mathrm{Nm}^{-2}$ for membrane M4; $938.3 \mathrm{Nm}^{-2}$ for membrane M5 to $662.3 \mathrm{Nm}^{-2}$ for membrane M6). The use of gauze as a solid supporting layer of the PSf/PVDF membrane has created membrane layer with higher mechanical strength than PSf/PVDF membrane that prepared without supporting layer [16].

\section{Membrane Performance}

\section{Filtration of pure water}

PSf/PVDF membrane permeability test carried out by pure water dead-end filtration. The permeability test resulted seems in Fig. 3.

Fig. 3 shows pure water permeability of PSf, PSf/PVDF, and PVDF membrane which precipitated using water nonsolvent. The added of PVDF to PSf polymer solution has increased the pure water permeability of PSf membrane. It is certainly not in line with the prediction that permeability will increase as a result of the increased in membrane pore size. In this state, the hydrophilic properties which increase with increasing of polar atomic $-\mathrm{CH}$ and $-\mathrm{CF}$ existence that have filled the membrane frame dominated by PSf has increased the pure water permeability of the membrane. Further, the domination of PVDF polymer in the casting solution has significantly increased the hydrophilic properties and prevent the occurrence of an increased porous layer in the membrane. This condition has resulted in an increase in the permeability of the membrane to pure water. Thus it can be said that the pure water flux of the PSf/PVDF membrane is determined by the thickness of the porous layer and hydrophilic properties of the membrane.

It is in line which the judging result from the Fig. 2a and $2 \mathrm{~b}$ in which the thickness of the porous layer on the membrane M3 and M4 look similar with more porous surface morphology than membrane M5 and M6. From Fig. $2 \mathrm{c}$ and $2 \mathrm{~d}$, it can be seen that membrane M5 and M6 have a denser structure as a result of the increasing quantity of PVDF particles which decomposes within the

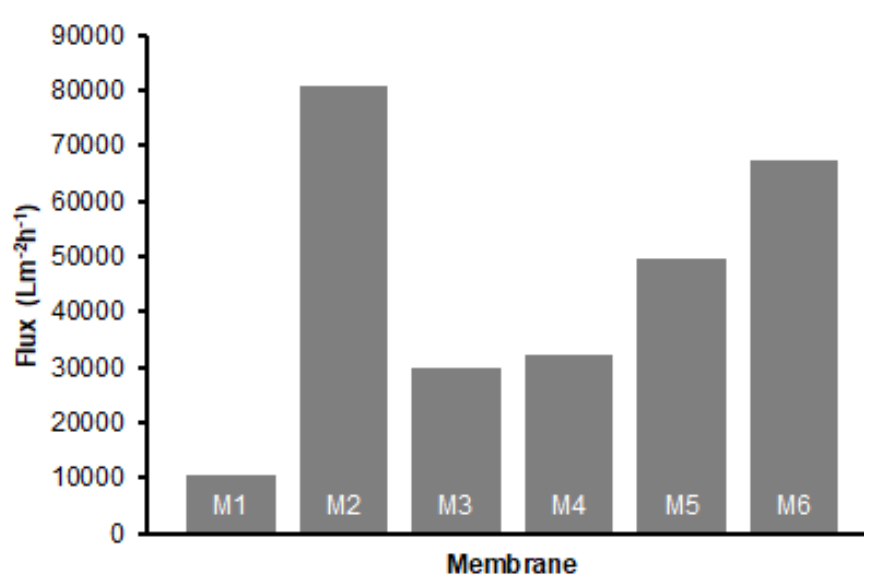

Fig 3. Pure water flux of PSf/PVDF blend membranes with different casting solution compositions

PSf polymer framework. This phenomenon can be seen explicitly through a comparison with Fig. $2 \mathrm{e}$ and 2f which shows the cross-section morphology of the PSf and PVDF membranes. Compared with the Fig. $2 a, 2 b, 2 c$, and 2d, Fig. 2e shows that membrane M1 has a porous layer with a higher thickness and lower dense pore as well as limited porosity compared to membrane M2 that seems in the Fig. 2f. The combination of higher hydrophilic properties and lower thickness of membrane porous layer then resulted in a difference in the pure water flux of the PSf/PVDF membrane.

\section{Thermal Stability and Chemical Resistance of the Membrane}

\section{Membrane thermal stability}

Thermogravimetric analysis results show that PSf and PVDF were decomposed in some steps as shown in Fig. 4. The decomposition is indicated by the weight lost during the temperature increases. The first and second mass reduction which are detected at around $100-200{ }^{\circ} \mathrm{C}$ corresponds to the releasing of water as vapor [17] and $220-260{ }^{\circ} \mathrm{C}$ for the releasing of NMP that adsorbed on the surface of PSf/PVDF membrane. The third mass reduction occurs at about $340-360^{\circ} \mathrm{C}$. It is predicted that the third mass reduction is caused by the decomposition of PVDF. The result is consistent with those reported in [18] that PVDF was decomposed 


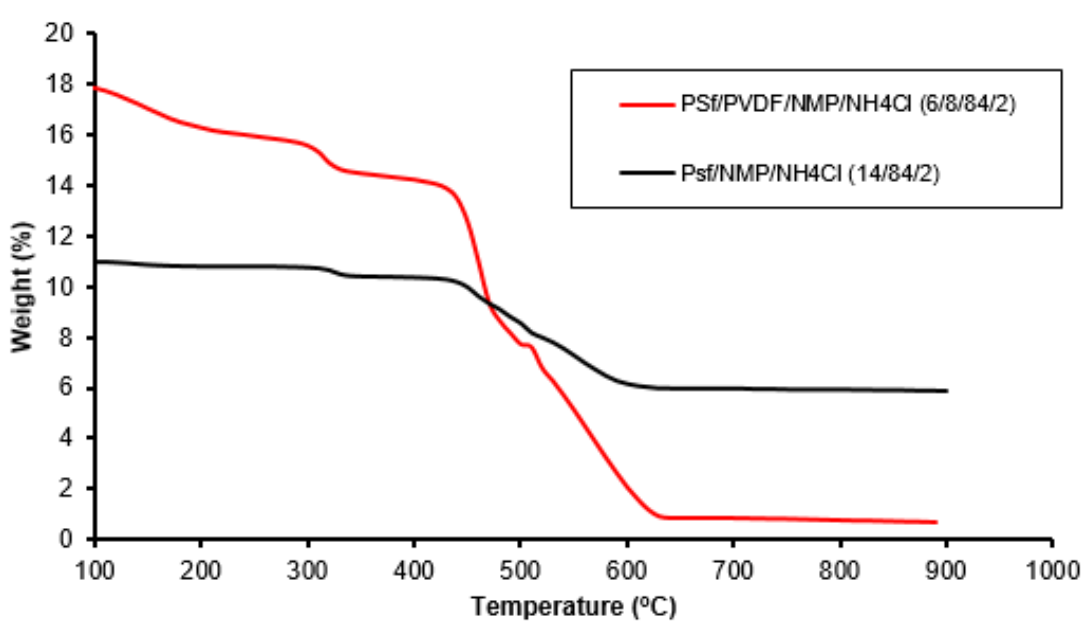

Fig 4. Thermogram TGA of M5 and M1

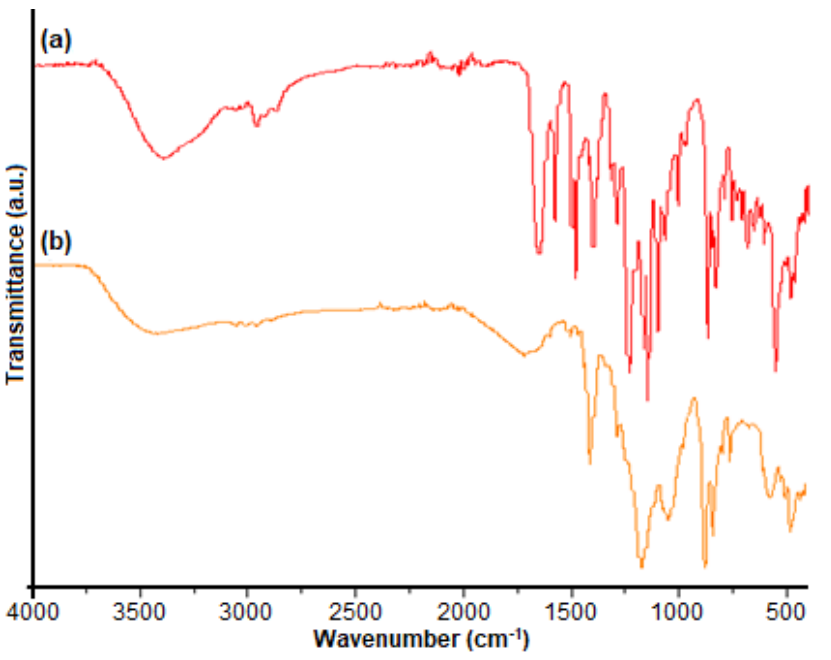

Fig 5. Infrared spectra of M5. (a) before; and (b) after immersion in $\mathrm{H}_{2} \mathrm{SO}_{4}$

at about $375{ }^{\circ} \mathrm{C}$. While the fourth mass reduction at about $460{ }^{\circ} \mathrm{C}$ that was caused by the decomposition of PSf. These data indicate that its lower thermal stability of PSf/PVDF than PSf membrane.

\section{Membrane chemical resistance}

The functional group test result using FTIR (see Fig. 5) has shown the better resistance of PVDF in sulfuric acid compared with PSf. This seems from the disappearance of the characteristic peak on the infrared spectra of PSf/PVDF membrane that has been immersed in sulfuric acid $98 \%(\mathrm{v} / \mathrm{v})$ for $24 \mathrm{~h}$. The characteristic peak intended are in the wavenumber of $1643 \mathrm{~cm}^{-1} \quad(\mathrm{C}=\mathrm{C}$ alkene $) ; 1643 ; 1584 ; 1504$; and $1487 \mathrm{~cm}^{-1}$ ( $\mathrm{C}=\mathrm{C}$ aromatic); also $1149 \mathrm{~cm}^{-1}$ (C-O ether). This is evident from the infrared spectra of PSf/PVDF before and after immersion process in sulfuric acid solution in Fig. 5.

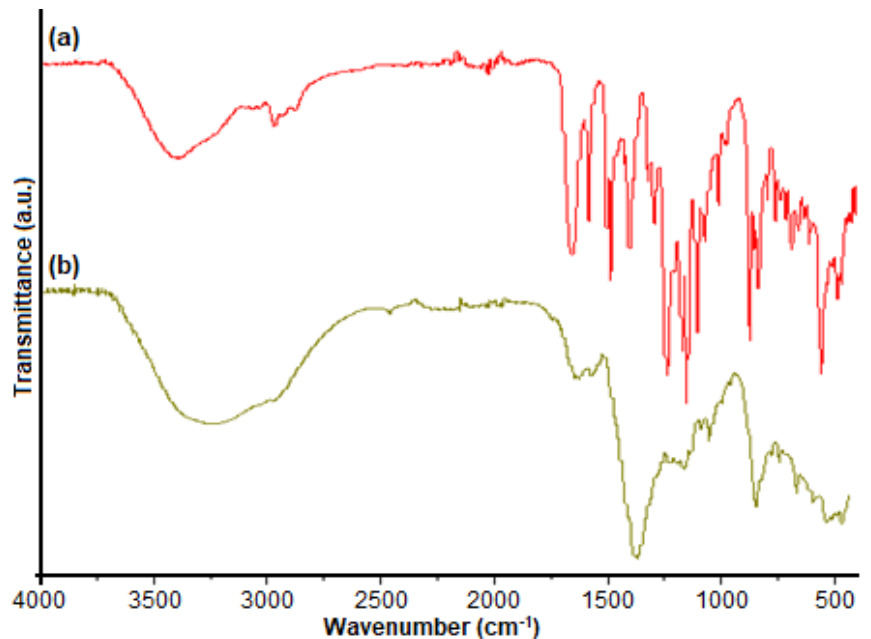

Fig 6. Infrared spectra of M5. (a) before; and (b) after immersion in $\mathrm{NaOH}$

The chemical resistance result of PSf/PVDF membrane against alkaline environment shows that PSf/PVDF membrane has not resistance to alkaline environment despite very dilute concentration. This looks from the detection of physical changes on the PSf/PVDF membrane which gradually become black after immersion process in sodium hydroxide. The black color formed more concentrated with the increasing concentration of sodium hydroxide are used.

Fig. 6 shows the occurrence of significant changes in the peak intensity of the functional group $-\mathrm{HF}$ at the wavenumber $1105 \mathrm{~cm}^{-1}$ and the disappearance of the peak at the wavenumber 1014 and $1080 \mathrm{~cm}^{-1}$. This condition indicates that the treatment of the alkaline environment has made dehydrofluorination on the membrane, i.e. losing functional group -HF. Thus it can be said that the color changes of PSt/PVDF membrane gradually from white 
to black after alkaline treatment is because of the dehydrofluorination of PVDF compound in the composite structure. These conditions indicate that although it is known to have good chemical resistance, the results of this study show that PSf/PVDF membrane has good thermal resistance in the base environment $(\mathrm{NaOH})$ to concentrations below $80 \%(\mathrm{w} / \mathrm{v})$. This fact corresponds to that reported by a number of researchers assert that there has been a color change from white to brown and finally black after immersing process in an alkaline solution for a few hours [18-21]. The formation of PVDF film colors become darker after treatment in aqueous hot alkaline shows have been onset the formation of $\mathrm{C}=\mathrm{C}$ bonds caused by dehydrofluorination on the PVDF polymer chain.

Infrared spectra data in Fig. 6 shows that the lower chemical resistance of PSf/PVDF on the alkaline environment is more affected by the weakness of PVDF in alkaline solution. This seems from the PSf characteristic peak that more detected compared with PVDF in the infrared spectra of PSf/PVDF membrane. The dominance of the PVDF influence in determining the chemical resistance of PSf/PVDF membrane influenced directly by the domination of the PVDF polymer in the casting solution, i.e. 6:8 wt\%.

\section{CONCLUSION}

The effect of casting solution composition against membrane characteristics: the PVDF polymer addition has resulted in an increase in the permeability as a result of hydrophilic nature increases in line with the decrease in the thickness of the porous layer. This PSf/PVDF membrane has smaller pore size with lower mechanical strength compared to PSf membrane which prepared with the same conditions. The TGA test analysis results show the lower thermal stability of the PSf/PVDF membrane than PSf membrane. The FTIR test analysis results show the higher and lower chemical resistance of PSf/PVDF membrane than PSf membrane, each in the acid and alkaline environment.

\section{ACKNOWLEDGEMENT}

The authors acknowledged the financial support by Indonesian Ministry of Higher Education, Research and Technology under The college's flagship research scheme No. 0004.4/UN38.11-P/LT/2016 and technical support from the Laboratory of Energy Studies - LPPM ITS and Laboratory of Material and Energy - Chemistry Department ITS.

\section{REFERENCES}

[1] Baker, R.W., 2004, Membrane Technology and Applications, $2^{\text {nd }}$ ed., John Wiley \& Sons, Ltd., Chichester, England, 1.

[2] Kusumawati, N., Koestiari, T., and Monica, M., 2015, The influence of casting solution and stirring conditions against mechanical strength and performance of polyvinylidene fluoride (PVDF)polysulfone (PSf) composite membrane on textile industrial wastewater treatment, Res. J. Pharm. Biol. Chem. Sci., 6, 271-280.

[3] Hilal, N., Ogunbiyi, O.O., Miles, N.J., and Nigmatullin, R., 2005, Methods employed for control of fouling in MF and UF membranes: A comprehensive review, Sep. Sci. Technol., 40 (10), 1957-2005.

[4] Matsuura, T., 1994, Synthetic Membranes and Membrane Separation Processes, CRC Press Inc., Florida, USA, 11-12.

[5] Le-Clech, P., Chen, V., and Fane, T.A.G., 2006, Fouling in membrane bioreactors used in wastewater treatment, J. Membr. Sci., 284 (1-2), 17-53.

[6] Hong, S.P., Bae, T.H., Tak, T.M., Hong, S., and Randall A., 2002, Fouling control in activated sludge submerged hollow fiber membrane bioreactors, Desalination, 143 (3), 219-228.

[7] Jamil, A., Ching, O.P., and Shariff, A.M., 2016, Minimizing morphological defects of PEI hollow fibre membrane by optimizing the dope viscosity, ARPN J. Eng. Appl. Sci., 11 (3), 1687-1690.

[8] Yan, L., Li, Y.S., Xiang, C.B., and Xianda, S., 2006, Effect of nano sized $\mathrm{Al}_{2} \mathrm{O}_{3}$-particle addition on PVDF ultrafiltration membrane performance, $J$. Membr. Sci., 276 (1-2), 162-167.

[9] Oh, S.J., Kim, N., and Lee, Y.T., 2009, Preparation and characterization of $\mathrm{PVDF} / \mathrm{TiO}_{2}$ organicinorganic composite membranes for fouling resistance improvement, J. Membr. Sci., 345 (1-2), 13-20.

[10] Maharani, K.D.A., and Kusumawati, N., 2016, The effect of casting solution and non solvent composition on the performance of polysulfone membranes against chromium (VI), Res. J. Pharm. Biol. Chem. Sci., 7, 496.

[11] Alamery, H.R.D., Hatim, M.D.I., and Ahmad, M.S., 2016, A study of the effects of adding PEG on the properties and morphology of asymmetric membranes comprising PVDF-HFP co-polymer fabricated by phase inversion method, ARPN J. Eng. Appl. Sci., 11 (11), 7130-7140. 
[12] Rahimpour, A., and Madaeni, S.S., 2007, Polyethersulfone (PES)/cellulose acetate phthalate (CAP) blend ultrafiltration membranes: Preparation, morphology, performance, and antifouling properties, J. Membr. Sci., 305 (1-2), 299-312.

[13] Albrecht, W., Weigel, T., Schossig-Tiedemann, M., Kneifel, K., Peinemann, K.V., and Paul, D., 2011, Formation of hollow fiber membranes from poly(ether imide) at wet phase inversion using binary mixtures of solvents for the preparation of the dope, J. Membr. Sci., 192 (1-2), 217-230.

[14] Nunnes, S.P., and Peinemann, K.V., 2006, Membrane Technology in the Chemical Chemistry Industry, WILEY-VCH Verlag GmbH \& Co. KGaA, Weinheim, Germany, 23-25.

[15] Voicu, S.I., Aldea, F., Răduţ, M., and Nechifor, G., 2008, Nanostructured polysulfone composite membrane, U.P.B. Sci. Bull., Ser. B, 70 (3), 39-46.

[16] Wu, L., Sun, J., and Wang, Q., 2006, Poly(vinylidene fluoride)/polyethersulfone blend membranes: Effect of solvent sort, polyethersulfone and polyvinylpyrrolidone concentration on their properties and morphology, J. Membr. Sci., 285 (12), 290-298.

[17] Kusumawati, N., Koestiari, T., and Monica, M., 2015, The influence of casting solution composition and stirring conditions against mechanical strength and performance of polyvinylidene fluoride (PVDF)-polysulfone (PSf) composite membrane on textile industrial wastewater treatment, Res. J. Pharm. Biol. Chem. Sci., 6 (1), 271-280.

[18] Setyaningsih, E.P., Machfudzoh, M., Utomo, W.P., and Fansuri, H., 2016, Preparation of $\mathrm{CiO}_{3}$ asymmetric membrane using polyetherimide as binder polymer, Indones. J. Chem., 16 (1), 20-24.

[19] Liu, F., Hashim, N.A., Liu, Y., Abed, M.R.M., and $\mathrm{Li}, \mathrm{K} ., 2011$, Progress in the production and modification of PVDF membranes, J. Membr. Sci., 375 (1-2), 1-27.

[20] Voicu, S.I., Stanciu, N.D., Nechifor, A.C., Vaireanu, D.I., and Nechifor, G., 2009, Synthetis and characterization of ionic conductive polysulfone composite membrane, Rom. J. Inf. Sci. Technol., 12 (3), 410-422.

[21] Ningrum, R.D.C., and Kusumawati, N., 2016, Development and characterization of polysulfone/polyvinylidene fluoride blend membrane induced by delayed liquid-liquid demixing, Int. J. Adv. Sci. Eng. Inf. Technol., 6 (5), 716-722. 